\title{
FATORES QUE CONDICIONAM A PRESENÇA E DISPERSÃO DE MINERAIS DE FERRO NOS SEDIMENTOS ARENOSOS DAS CALHAS, VÁRZEAS E TERRAÇOS DOS RIOS QUE DRENAM O QUADRILÁTERO FERRÍFERO (MG).
}

\author{
FACTORS THAT INFLUENCE THE OCCURRENCE AND DISPERSION OF IRON \\ MINERALS IN SANDY SEDIMENTS OF TERRACES AND FLOODPLAINS OF RIVERS \\ DRAINING THE QUADRILATERO FERRIFERO (MG). \\ Paulo de Tarso Amorim CASTRO¹, Cláudio Eduardo LANA', Tiago Oliveira \\ ROBERTTI², Maria Eugênia Silva de SOUZA ${ }^{1}$, Mário QUINTAES ${ }^{1}$, Maria Elisa Martins \\ MORAES ${ }^{1}$, Neylliane Cristina Cruz da SILVA ${ }^{1}$ \\ (1) Departamento de Geologia, Escola de Minas - Universidade Federal de Ouro Preto. Emails: ptacastro@ gmail.com; \\ claudiolana@gmail.com; messouza.op@gmail.com; maquintaes@yahoo.com.br; migamartins@ hotmail.com; \\ neylliane.geo@gmail.com \\ (2) Instituto Federal do Espírito Santo. Email: robertti.geologia@gmail.com
}

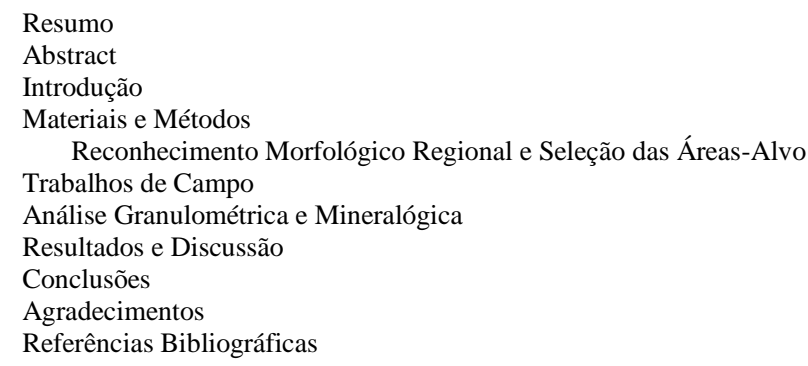

\begin{abstract}
RESUMO - Este trabalho apresenta os resultados de estudos sedimentológicos realizados ao longo dos cursos de água das bacias hidrográficas dos rios Piracicaba, das Velhas e Doce que drenam as áreas das minas de ferro do Quadrilátero Ferrífero. Foram realizadas caracterizações sedimentológicas e mineralógicas de amostras coletadas na calha dos cursos de água visando obter a concentração de minerais de ferro. Paralelamente, foram analisadas amostras de sedimentos coletados nas várzeas e terraços, com objetivo de obter elementos de comparação temporal da ocorrência de minerais de ferro em sedimentos aluviais depositados anteriormente à instalação das minas na região. Os resultados obtidos indicam que a presença de barramentos nos cursos de água interfere na dispersão dos minerais de ferro. A malha ferroviária utilizada como escoamento da produção de ferro ao longo do rio Piracicaba atua como fonte secundária de minerais de ferro nas várzeas e na calha do rio. Quando comparados à concentração de minerais de ferro nos terraços, os sedimentos das calhas fluviais mostram substancial aumento da concentração, indicando que a ação antrópica é a causadora deste aumento a despeito das ações mitigadoras que a legislação ambiental preconiza.
\end{abstract}

Palavras-chave: minerais de ferro, aluviões, Quadrilátero Ferrífero.

\begin{abstract}
This work presents the results of sedimentological studies conducted along the watercourses of the Piracicaba, Velhas and Doce river basins that drain the iron mining areas of the Quadrilatero Ferrífero. Sedimentological and mineralogical characterization of sandy sediment samples collected in the channel of the water courses was carried out in order to obtain the concentration of iron minerals. In addition, samples of sediments from the floodplains and terraces were collected and analyzed, with the pourpose of make temporal comparison among sandy iron mineral concentration in alluvial sediments deposited prior to the installation of the mines in the region. The results indicate that the presence of dams in the watercourses interferes with the dispersion of iron minerals. The railroad used in transport of the iron production along the Piracicaba river valley acts as a secondary source of iron minerals in the floodplains and in the river channel. When compared to the concentration of iron minerals in the terraces, the sediments of the river channels show a substantial increase in concentration, indicating that the anthropic action is the main cause of this increase despite mitigating actions regulated by environmental laws.
\end{abstract}

Keywords: iron minerals, alluvium, Quadrilatero Ferrifero.

\section{INTRODUÇÃO}

A preservação e a restauração de rios têm sido atualmente evidenciadas devido ao acelerado processo de sua degradação e ao aumento das demandas sociais por recursos hídricos. $\mathrm{O}$ incremento das atividades industriais e agropecuárias e a forte demanda mundial por commodities, em especial os produtos minerais, ao longo dos primeiros 15 anos do século XXI, fez com que aumentasse a preocupação da sociedade no que diz respeito à água como recurso e ao estágio de degradação dos sistemas fluviais.

O Quadrilátero Ferrífero (MG) é atualmente um exemplo desta situação. Esta região, localizada no centro-sul de Minas Gerais, que passou a ser chamada de Quadrilátero Ferrífero no início da década de 1930, concentra as principais minas de minério de ferro e de ouro 
do sudeste do país. Em termos fisiográficos, o Quadrilátero Ferrífero apresenta um relevo caracterizado por serras alongadas que dão a conformação quase retangular que fundamentou o seu nome. As bacias do rio Doce e Rio São Francisco têm afluentes nos quais boa parte das cabeceiras se situa no conjunto de serras que delineiam o Quadrilátero Ferrífero e onde estão situadas as principais minas e jazidas de ferro do país.

Com uma população estimada em 4.200.000 habitantes, cerca de $22 \%$ da população mineira e um PIB que representa 26,8\% do de Minas Gerais, o Quadrilátero Ferrífero é palco de conflitos relativos ao uso do espaço e aos recursos hídricos (Castro et al., 2015). A expansão acelerada da região metropolitana de Belo Horizonte com condomínios da classe média-alta instalando-se na periferia de áreas tradicionalmente mineradoras expôs as preocupações concernentes à influência da mineração, sobretudo de ferro, na degradação das águas e no grau de assoreamento dos rios da região.

Dados do DNPM (2009) mostram que, em 2007, saíram das minas do Quadrilátero Ferrífero $72 \%$ da produção brasileira de ferro, que alcançou 354,67 milhões de toneladas. A extração e beneficiamento de cerca de 250 milhões de toneladas de ferro em uma região montanhosa, com índices pluviométricos ao redor dos $1300 \mathrm{~mm}$ anuais exigem um planejamento eficaz das barragens de rejeito e das bacias de contenção de estéreis. O mesmo esforço na produção de ferro pode não ter sido acompanhado por medidas adequadas de contenção de rejeitos e estéreis se considerarmos que ao longo dos cinquenta anos de exploração constante do ferro na região a sua produção saltou de cerca de 31 mil toneladas em 1958 (Castro et al. 2015) para as 250 milhões de toneladas anuais em 2007 e cerca de 265 milhões de toneladas em 2013 (DNPM, 2015). Pode-se dizer que até a metade da década de 1970 a preocupação ambiental no que diz respeito à contenção de material estéril e rejeitos não constava como pauta importante na agenda das empresas de mineração. Depois de incorporada a agenda ambiental nas diretivas das minas, a evolução na explotação de ferro em ritmo intenso tem levado ao esgotamento rápido da capacidade de retenção das barragens de rejeito e das bacias de contenção de sedimentos das minas. Assim, a mineração de ferro é apontada como a principal causadora do entulhamento das calhas dos rios.

Por outro lado, os processos intempéricos e erosivos no Quadrilátero Ferrífero, desde pelo menos o Neógeno, os reflexos da interação entre os biomas, as alternâncias climáticas e a sua diversidade litoestrutural, concorreram para a modelagem do relevo regional, onde as cristas das montanhas são quase que totalmente modeladas em quartzitos e itabiritos, recobertos por cangas (lateritas) (Barbosa \& Rodrigues, 1965). Frequentemente, as cangas, compõem o topo e flancos destas serras, bem como patamares menos elevados (Varajão, 1991).

Em resposta aos processos erosivos é de se esperar que os aluviões dos rios que nascem no Quadrilátero Ferrífero contenham fragmentos de rochas e minerais cujas áreas-fontes sejam justamente aquelas onde afloram os quartzitos, os itabiritos e as cangas. Nestas condições, o estudo da dispersão dos minerais e fragmentos de rocha ao longo dos depósitos aluviais précolombianos das redes de drenagem que nascem na região pode ter significado para o entendimento do impacto da mineração no aumento da disponibilidade de sedimentos atuais nas calhas dos rios.

Assim, a presença de minerais de ferro, tais como hematita, magnetita e goetita, nos sedimentos que compõem os terraços, as planícies e as calhas dos rios que nascem nestas serras se relacionam à dois principais processos: a dispersão natural dos minerais de ferro nos cursos de água que nascem em serras formadas por rochas ricas em ferro e a influência antrópica no processo de dispersão, em função das lavras de minério de ferro e da ocupação nas áreas onde afloram estas rochas, sobretudo aquelas pertencentes aos supergrupos Minas (Castro et al., 2015).

Este trabalho apresenta os resultados de estudos sedimentológicos que buscam caracterizar a ocorrência de minerais de ferro ao longo dos cursos de água das bacias hidrográficas dos rios Piracicaba, das Velhas e Doce (Figura 1).

Diversos fatores influenciam a dispersão de minerais de ferro nestas bacias. Fatores antrópicos como a presença de minas de ferro junto às nascentes de alguns componentes dessas 
bacias e demais intervenções antrópicas, como a presença de barramentos ao longo de seus cursos, são analisados. Em uma perspectiva histórica, a análise de amostras dos terraços, portanto anteriores à instalação da mineração de ferro no Quadrilátero Ferrífero oferece oportunidade de avaliar objetivamente a influência antrópica em sua dispersão nas bacias estudadas.

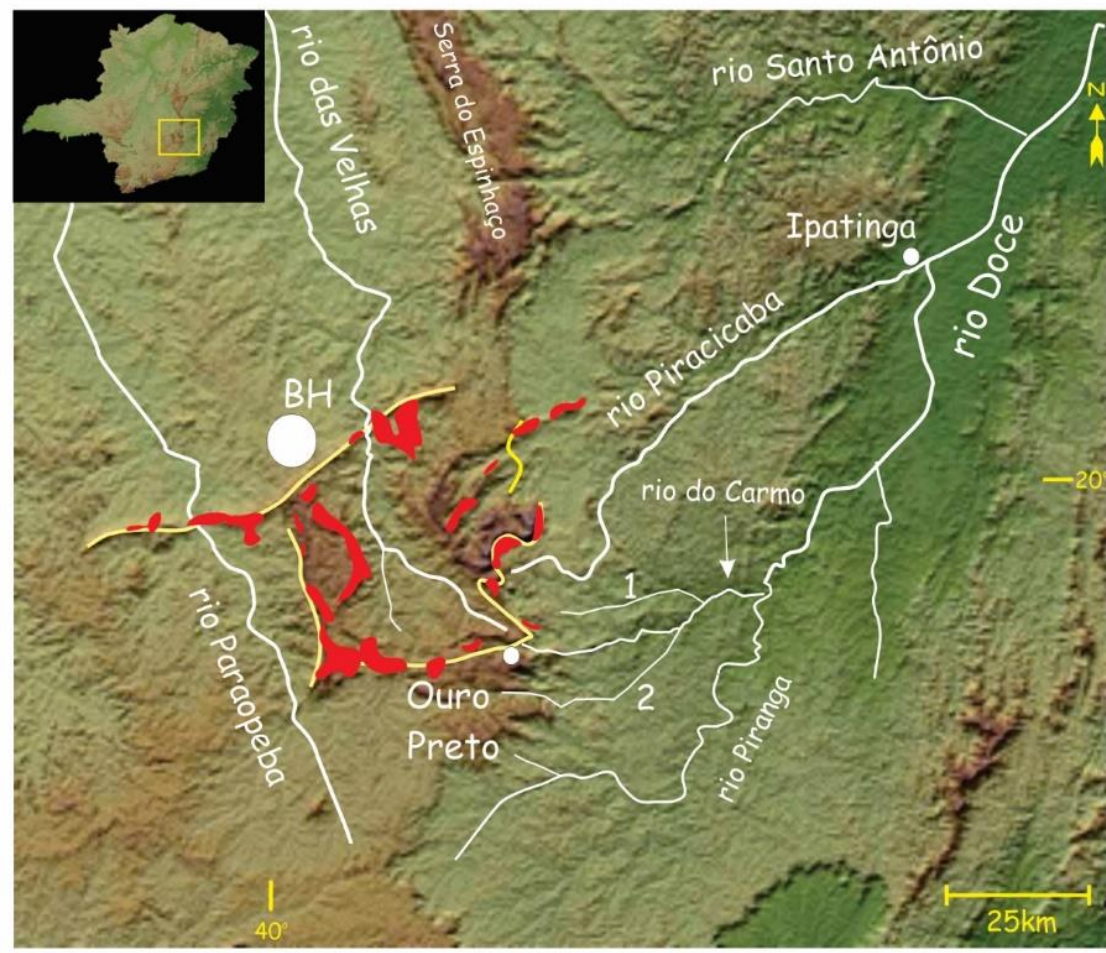

1 - rio Gualaxo do Norte 2 - rio Gualaxo do Sul

Figura 1 - O Quadrilátero Ferrífero situa-se na região centro-sul de Minas Gerais. Os seus limites marcados pelos alinhamentos das serras estão salientados em traços amarelos. São mostrados os principais rios que drenam o Quadrilátero Ferrífero, com destaque para aqueles que estão analisados neste texto e para as zonas de explotação do ferro, marcadas em vermelho.

São frequentes os estudos de presença de minerais associados a recursos minerais nos sedimentos existentes ao longo das calhas dos rios e nas aluviões. Boa parte deles visam a prospecção de recursos minerais (por ex., Hale \& Plant, 1995) enquanto, outros, mais recentemente, tratam do impacto da mineração nos sedimentos, sobretudo de elementos como o arsênio, mercúrio, crômio, chumbo e o cádmio (por ex. Botsou et al. 2011; Mohiuddin et al., 2010; Rodrigues, 2012).

Nas bacias dos rios Doce e Velhas, estudos geoquímicos foram realizados objetivando entender os impactos ambientais decorrentes da mineração de ouro e de ferro, sobretudo na geoquímica de águas e sedimentos (Guedes et al., 2005; Rodrigues et al., 2012; Costa, 2001; Viglio \& Cunha, 2010; Couto, 2011 e Mendonça, 2012).

Nos principais afluentes que compõem as bacias do Rio das Velhas e do Rio Doce, no Quadrilátero Ferrífero e no seu flanco leste, são reconhecidos terraços aluviais preservados ao longo das calhas de drenagem e em diversos níveis topográficos (por exemplo, Valadão e Silveira, 1992; Magalhães Jr e Saadi, 1994; Bacellar et al., 2005; Raposo et al., 2008; Costa et al. 2006; Cherem et al., 2008; Lana e Castro, 2010; Magalhães Jr et al., 2012; Barros e Magalhães Jr., 2013; Rodrigues, 2012). Os terraços mais antigos da bacia do alto Rio das Velhas se apresentam escalonados. Na bacia do alto rio Conceição, afluente do rio Doce, foram identificados oito níveis, cujas idades mostram uma ampla dispersão com datações obtidas por Luminescência Opticamente Estimulada (LOE) entre 80,7 $\pm 6,8$ mil anos e 1,0 $\pm 0,14$ mil anos. Nas cabeceiras dos afluentes do Rio Doce (rios Conceição, Caraça, Barão de Cocais, Coqueiros e Carmo) também estão presentes oito níveis deposicionais com idades variando entre 139, 3 $\pm 13,2$ mil anos a 1,9 $\pm 0,3$ mil anos (Barros 2015). Em todos os vales os terraços possuem idades pré-colombianas. 


\section{MATERIAIS E MÉTODOS}

Os estudos foram realizados em sedimentos coletados nas calhas dos rios, nas paredes laterais dos cursos de água e nos terraços.

\section{Reconhecimento morfológico regional e seleção das áreas-alvo}

Essa etapa teve como objetivo principal reconhecer os elementos geomorfológicos presentes da região de estudo, com a finalidade de identificar os segmentos fluviais que apresentavam planícies e terraços aluviais. Para isso, utilizaram-se mapas topográficos e geológicos, fotografias aéreas, ortofotos, imagens de satélite e imagens Google Earth. Dentre os segmentos fluviais, foram selecionados aqueles com presença de planícies e terraços aluviais, bem como segmentos de rios a montante e a jusante de confluências de tributários que drenam tanto áreas de mineração de ferro quanto dos que drenam áreas ricas em minerais de ferro sem interferência de mineração e com pouca interferência antrópica direta.

\section{TRABALHOS DE CAMPO}

Dos segmentos identificados previamente foram selecionados aqueles que apresentavam terraços e planícies com boas condições de acesso, os quais foram georreferenciados com uso de GPS Garmin map76S.

Nas escarpas dos terraços e nas paredes dos canais foram levantados perfis de fácies sedimentares conforme descrito em Compton (1985) e Lindholm (1987).

Os perfis foram levantados em escala 1:100, com uso de lupa de mão, trena, vara de Jacob (graduada de 10 em 10 centímetros), câmera fotográfica digital, martelo e cartela granulométrica, baseada na classificação de Wentworth (1922, segundo Pettijohn, 1975).

A classificação das fácies sedimentares nos perfis baseou-se nos critérios propostos por Miall (1996), levando-se em consideração as estruturas sedimentares, características texturais (granulação, grau de seleção e arredondamento), composição mineralógica, bem como a presença ou ausência de conteúdo antropogênico.

Inicialmente foi feita a limpeza superficial dos terraços e das paredes do canal, a fim de retirar a vegetação presente e a cobertura superficial para melhor visualização das estruturas e da textura dos depósitos sedimentares. Para a limpeza dos perfis e coleta de amostra dos sedimentos utilizou-se enxada, facão e sacos plásticos devidamente identificados e selados imediatamente após a coleta.

Como estratégia de amostragem procurouse, sempre que possível obter amostras de sedimentos depositados em três diferentes períodos de tempo, porém em mesmas condições energéticas de deposição. Deste modo, foram coletadas amostras nos terraços, nas paredes e no assoalho dos canais (Figura 2). Nos três sítios de coleta em cada segmento de rio foram amostrados sedimentos arenosos transportados como carga de fundo, ou seja, na fração trativa. A opção pela amostragem na fração areia visou também reduzir a influência da infiltração de partículas nos sedimentos coletados nos terraços e nas planícies.

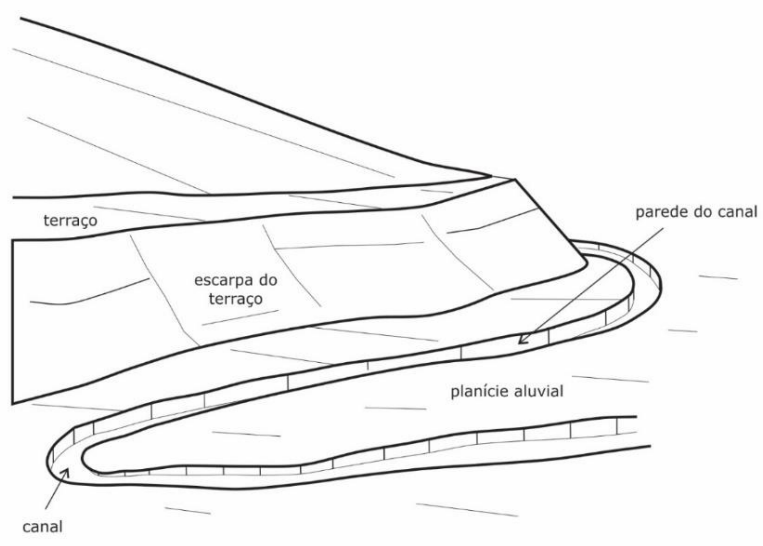

Figura 2 - Elementos geomórficos dos segmentos de rios estudados. Os perfis sedimentares foram levantados nas escarpas dos terraços e nas paredes dos canais, ao passo que as amostras foram coletadas tanto nas escarpas dos terraços e nas paredes dos canais quanto no assoalho dos canais. 
Nos estudos no vale do alto Rio das Velhas, as fácies arenosas presentes nas escarpas dos terraços e paredes dos canais estão associadas a condições de mais baixa energia. Assim, foram escolhidas as fácies arenosas que apresentavam ripples de corrente e camadas planas (laminação plano-paralela) para a amostragem. Para os afluentes do rio Doce, foram escolhidas fácies associadas a condições deposicionais de maior energia para amostragem. Portanto, buscou-se assegurar que os sedimentos amostrados foram transportados sob mesmas condições energéticas, tanto no registro sedimentar, quanto no leito do rio (Figura 3).

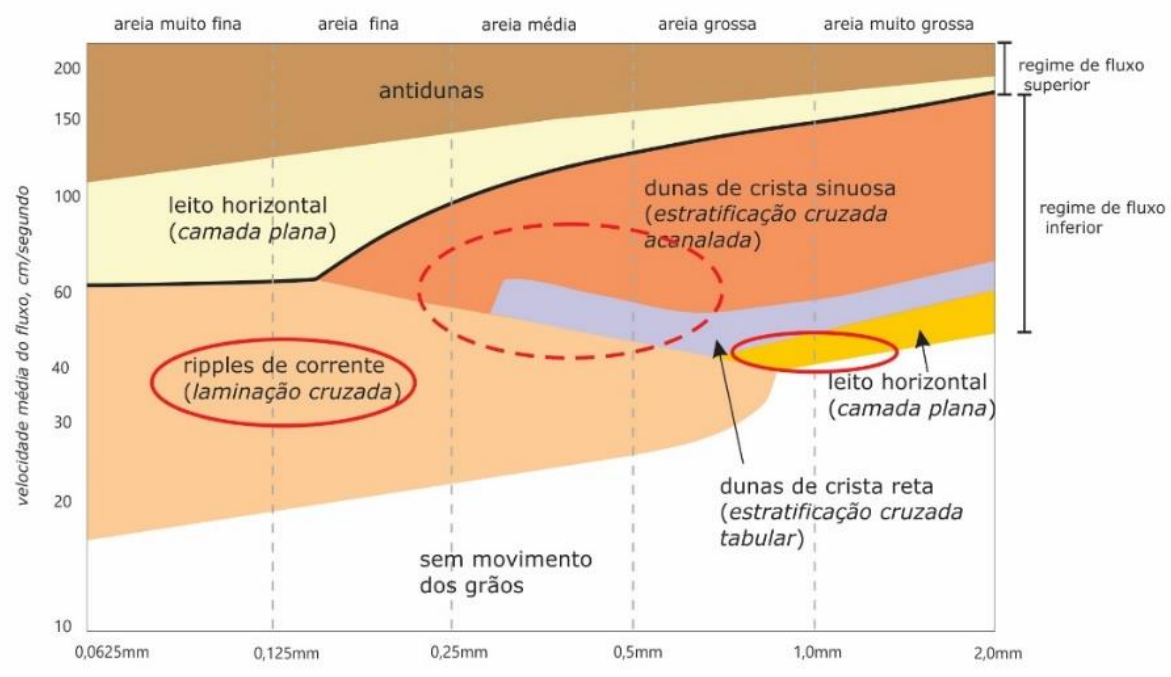

Figura 3 - Campo de estabilidade de formas de leito geradas por fluxo unidirecional de água. Gráfico de velocidade média de fluxo x tamanho médio dos grãos em uma profundidade de fluxo de cerca de $40 \mathrm{~cm}$. Modificado de Middleton \& Southward (1978). Nos estudos no vale do alto Rio das Velhas foram escolhidas as fácies arenosas que apresentavam ripples de corrente e camadas planas para a amostragem (elipse de contorno contínuo). Para os afluentes do rio Doce, foram escolhidas fácies mais energéticas para amostragem como dunas de crista sinuosa e estratificações cruzadas (elipse de contorno tracejado).

\section{ANÁLISE GRANULOMÉTRICA E MINERALÓGICA}

Os sedimentos coletados passaram por análise granulométrica convencional por peneiramento. Nas amostras foram separados aleatoriamente 200 grãos de areia. Foram identificados os minerais componentes desta subamostragem em lupa binocular o Physis com aumento de até 45 vezes e Motic SMZ-168 com aumento de até 50 vezes. O reconhecimento dos minerais seguiu as características de identificação de minerais em grãos apresentadas por Pereira et al. (2005), Addad (2001) e Folk (1980). Os dados obtidos foram processados utilizando-se do programa Excel (Microsoft Office) para a elaboração dos gráficos.

\section{RESULTADOS E DISCUSSÃO}

Foram estudadas amostras de sedimentos das bacias hidrográficas dos rios Piracicaba, Gualaxo do Norte e Gualaxo do Sul, formadores do rio Doce, e rio Itabirito e o alto rio das Velhas. Em função de suas maiores dimensões, as bacias do rio Piracicaba e do alto Rio das Velhas tiveram um maior número de pontos de amostragem (Figura 4) em relação aos rios Gualaxo do Norte e do Sul (Figura 5). A possibilidade de acesso aos trechos selecionados também foi um fator determinante no número de pontos de coleta. As minerações de ferro ocorrem junto às cabeceiras de alguns afluentes destes rios, com exceção do rio
Gualaxo do Sul. Nas bacias do Rio Piracicaba e do alto rio das Velhas foram analisados alguns segmentos de rios cujas cabeceiras não se localizavam em rochas ricas em ferro e/ou sem mineração ativa.

Ao todo, foram analisados 39 terraços e 64 paredes de canais, resultando em 190 amostras coletadas. A Figura 6 mostra o número de pontos selecionados e suas características. Em alguns segmentos estudados não foram reconhecidos terraços e em outros as paredes dos canais estavam inaccessíveis, o que mostra a discrepância entre os números das terceira e quarta colunas da tabela 1. 

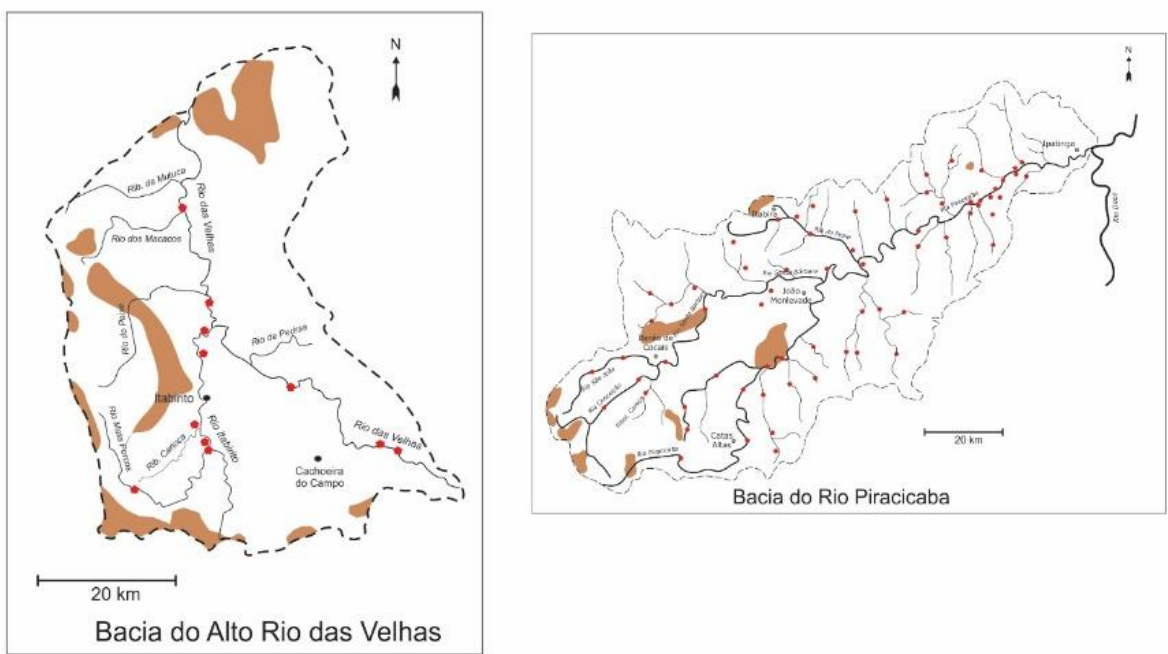

Figura 4 - As bacias do alto Rio das Velhas e do Rio Piracicaba abrangeram o maior número de pontos amostrados, marcados em vermelho. As linhas tracejadas marcam os limites das bacias e as manchas de cor marrom são as áreas de explotação de ferro, normalmente marcando as cristas das serras.
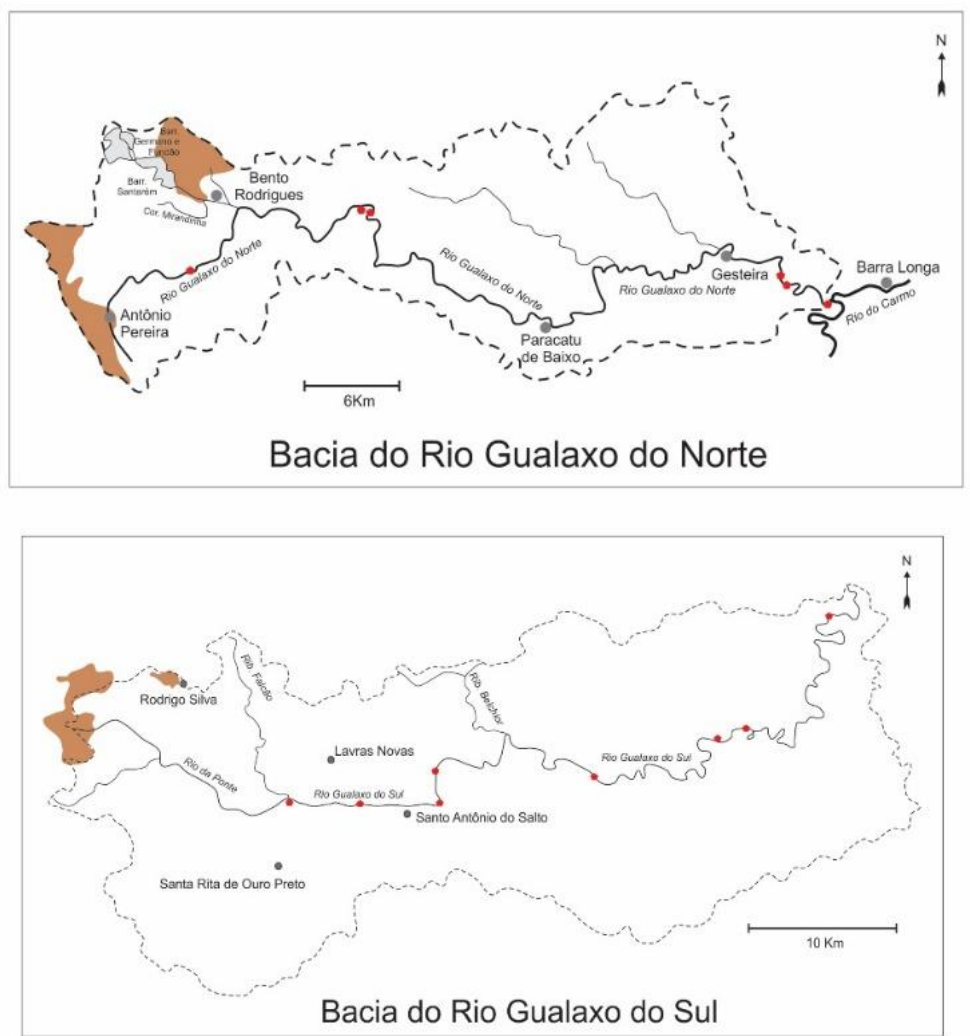

Figura 5 - As bacias dos rios Gualaxo do Norte e Gualaxo do Sul, de menores dimensões que os outros analisados apresentam poucos pontos passíveis de serem estudados (marcados em vermelho). As linhas tracejadas marcam os limites das bacias e as manchas de cor marrom são as áreas de explotação de ferro, normalmente marcando as cristas das serras.

Tabela 1 - Segmentos de rios estudados, número de perfis levantados e amostras coletadas.

\begin{tabular}{|l|l|l|l|l|}
\hline Rio & $\begin{array}{l}\text { Número de } \\
\text { segmentos } \\
\text { estudados }\end{array}$ & $\begin{array}{l}\text { Perfis } \\
\text { sedimentares } \\
\text { levantados } *\end{array}$ & $\begin{array}{l}\text { Amostras } \\
\text { Coletadas* }\end{array}$ & Fonte Bibliográfica \\
\hline Piracicaba & 68 & $\mathrm{ep}=22, \mathrm{pc}=50$ & $\mathrm{ep}=22, \mathrm{pc}=50, \mathrm{fc}=68$ & (Robertti, 2016) \\
\hline Gualaxo do Norte & 5 & $\mathrm{ep}=3, \mathrm{pc}=4$ & $\mathrm{ep}=3, \mathrm{pc}=4, \mathrm{fc}=4$ & (Souza, 2013) \\
\hline Gualaxo do Sul & 8 & $\mathrm{ep}=8, \mathrm{pc}=3$ & $\mathrm{ep}=5, \mathrm{pc}=3, \mathrm{fc}=8$ & (Quintaes, 2014) \\
\hline Alto rio das Velhas & 12 & $\mathrm{ep}=6, \mathrm{pc}=7$ & $\mathrm{ep}=6, \mathrm{pc}=7, \mathrm{fc}=12$ & $\begin{array}{l}\text { (Moraes, 2016; Silva, } \\
\text { 2016) }\end{array}$ \\
\hline
\end{tabular}

* ep=escarpa do terraço; $\mathrm{pc}=$ parede do canal; $\mathrm{fc}=$ fundo do canal 


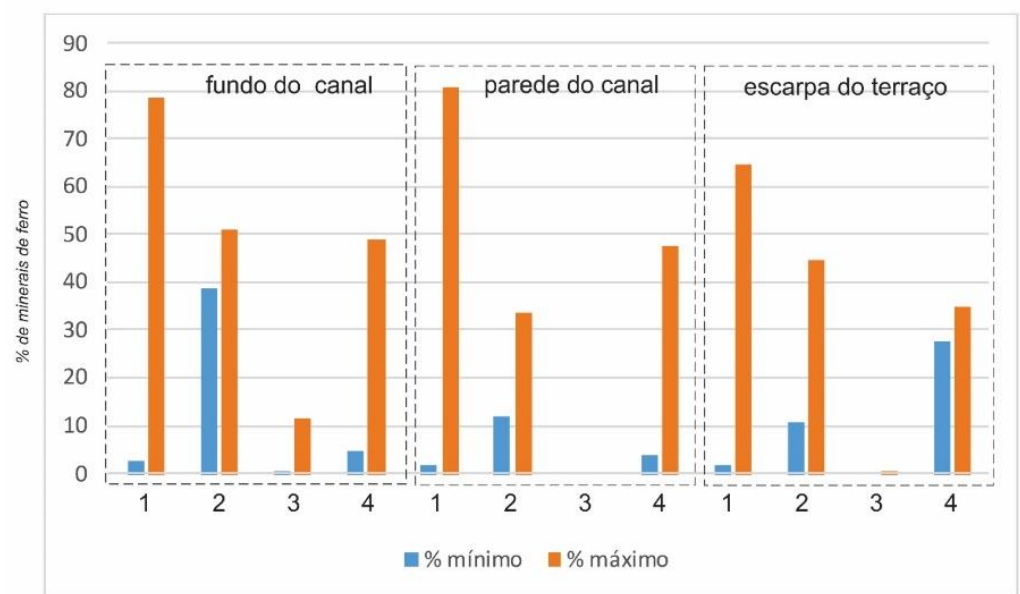

Figura 6 - Percentuais mínimos e máximos de minerais de ferro nos sedimentos coletados nos segmentos de rios das bacias estudadas. 1 Rio Piracicaba; 2 Rio Gualaxo do Norte; 3 Rio Gualaxo do Sul; 4 Alto Rio das Velhas.

O gráfico mostrado na figura 6 apresenta os percentuais máximos e mínimos de minerais de ferro presentes nas amostras de sedimentos de calha, das paredes dos canais e das escarpas dos terraços dos segmentos de rios estudados.

Alguns rios que compõem as bacias estudadas não têm rochas ferruginosas em suas cabeceiras, podendo contribuir negativamente para a proporção de minerais de ferro presentes nos sedimentos amostrados. Os dados de alguns rios cujas nascentes não drenam rochas ricas em ferro são mostradas na Figura 7. Comparando-se os dados de percentual de minerais de ferro nas escarpas de terraços mostrados na seção à direita, na figura 7 , com os dados presentes na figura 8 , pode-se ver que há uma grande variação em suas concentrações. Esta variação entre $0 \%$ e $65 \%$ indica que as rochas ferruginosas presentes nas cabeceiras dos rios foram importantes fontes de sedimentos durante o Holoceno.

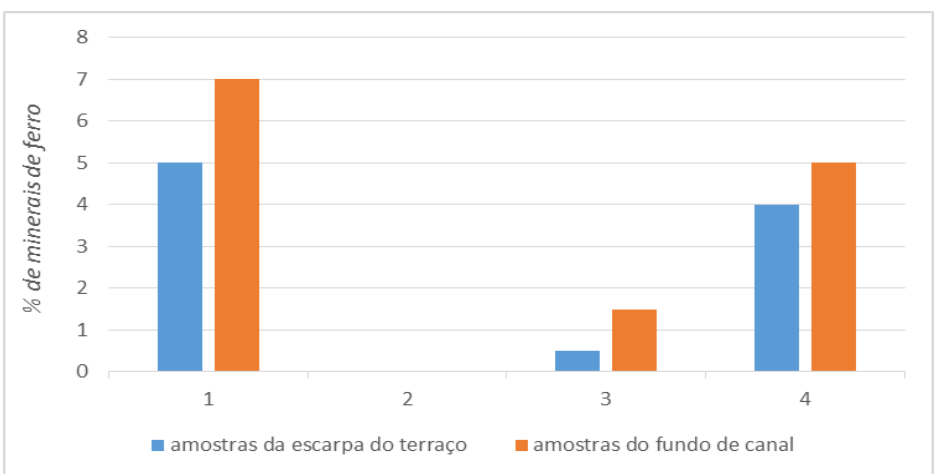

Figura 7 - Concentrações de minerais de ferro em afluentes que não drenam áreas de mineração. 1 Ribeirão Caraça (bacia do Rio Piracicaba); 2 Afluente do Rio Gualaxo do Norte; 3 Rio Maynart à jusante da Barragem de Tabuão, bacia do Gualaxo do Sul; 4 Ribeirão Carioca, bacia do alto Rio das Velhas

O rio Piracicaba, onde foi feita a maior amostragem, apresenta características naturais e intervenções antrópicas que interferem na distribuição de minerais de ferro nos sedimentos.

A Figura 8 mostra a disposição da desembocadura de afluentes que drenam áreas mineradas, como o rio Santa Bárbara, cujos afluentes provém de uma região com várias minas de ferro em atividade na região de Barão de Cocais e Santa Bárbara, e o rio do Peixe, que drena áreas da região de Itabira e que têm sido mineradas continuamente desde os anos 1960.
Também na figura 8 é apresentada a localização de intervenções antrópicas que são passiveis de interferir na disseminação de minerais de ferro ao longo do rio Piracicaba: as represas das usinas hidrelétricas de Piracicaba, Guiman Amorim e Antônio Dias, e parte do trajeto da Estrada de Ferro Vitória a Minas, que corre lateralmente ao canal do rio Piracicaba. O início das operações da Estrada de Ferro Vitória a Minas data de 1908, mas o trajeto atual sofreu modificações ao longo do tempo. 


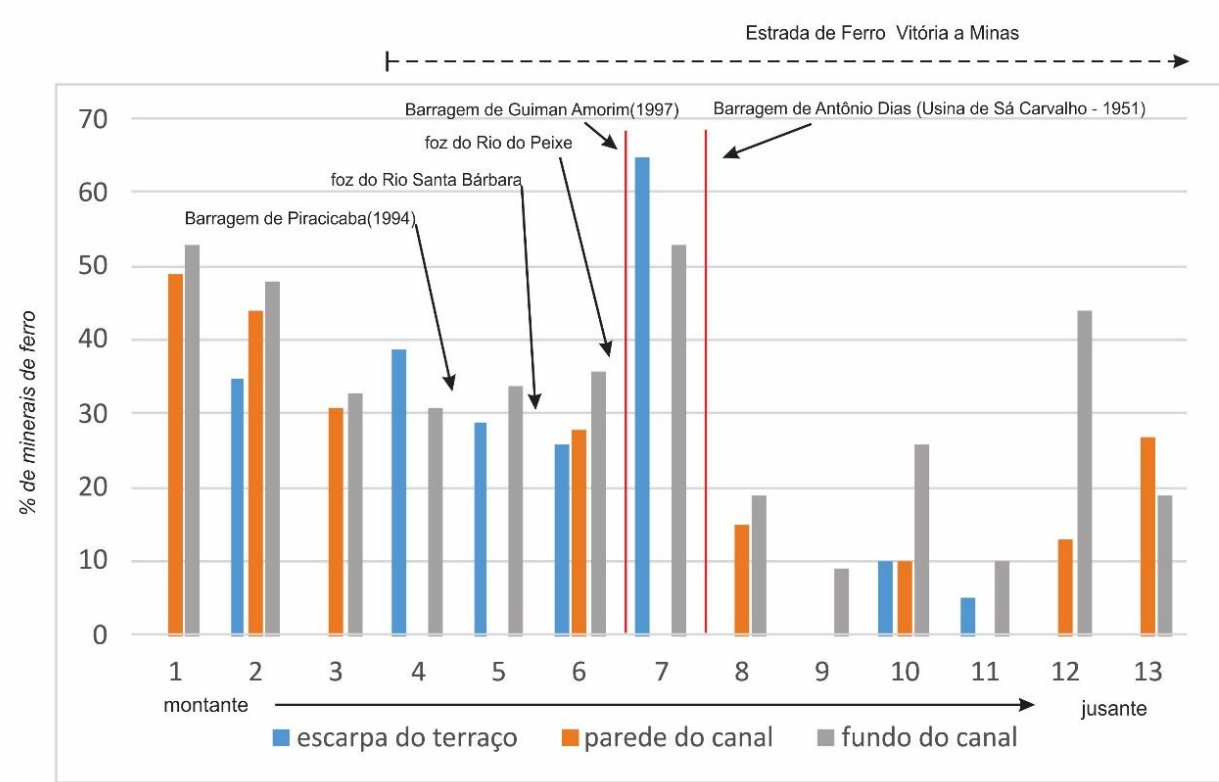

Figura 8 - Concentração de minerais de ferro em amostras obtidas nas escarpas dos terraços, nas paredes e no fundo dos canais e a posição da foz de rios que drenam áreas de mineração de ferro e das barragens ao longo do Rio Piracicaba. A linha tracejada mostra o trecho onde a Estrada de Ferro Vitória a Minas, principal escoadora de minério de ferro se posiciona ao longo do rio Piracicaba. Os números entre parêntesis indicam o ano do início de operação das usinas hidrelétricas.

O rio Gualaxo do Norte, onde ocorreu, em novembro de 2015, a tragédia da ruptura da barragem de Fundão, da mineração Samarco, apresenta caraterísticas diferentes da bacia do rio Piracicaba, por ser de menor dimensão e não conter muitos barramentos.

Em suas cabeceiras estão localizados os complexos mineradores de Timbopeba (Vale
S.A) e da Samarco e seus conjuntos de barragens, como é mostrado na figura 9.

$\mathrm{O}$ rio Gualaxo do Sul drena a região localizada a sul do Quadrilátero Ferrífero, onde são pouco frequentes as minas de ferro. A figura 10 mostra a distribuição da concentração de minerais de ferro de amostras recolhidas ao longo do seu curso.

Percentual de minerais de ferro nos sedimentos do Rio Gualaxo do Norte

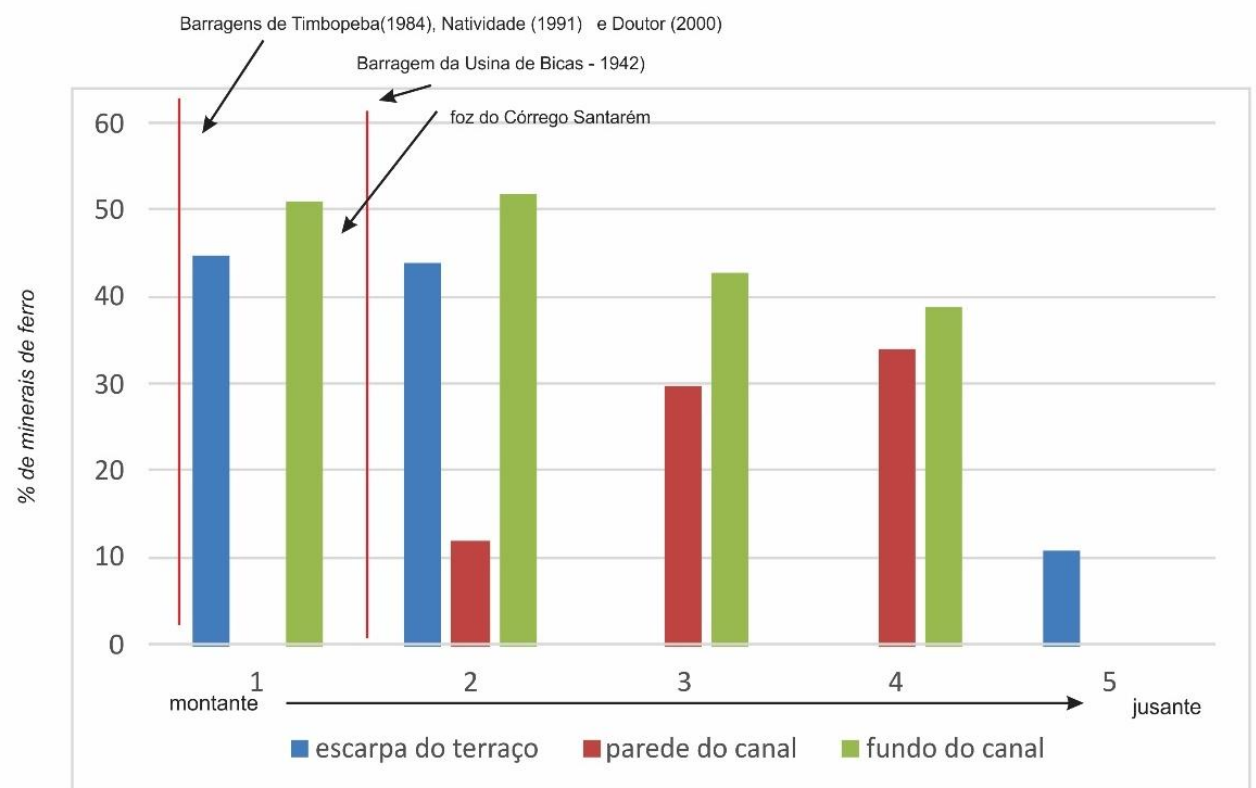

Figura 9 - Concentração de minerais de ferro em amostras obtidas nas escarpas dos terraços, nas paredes e no fundo dos canais ao longo do Rio Gualaxo do Norte. Nas suas cabeceiras estão localizados os complexos mineradores de ferro de Timbopeba (Vale S.A.) e da Samarco. Os números entre parêntesis indicam o ano do início de operação das barragens da mina de Timbopeba (Vale S.A.). 


\section{Percentual de minerais de ferro nos sedimentos do Rio Gualaxo do Sul}

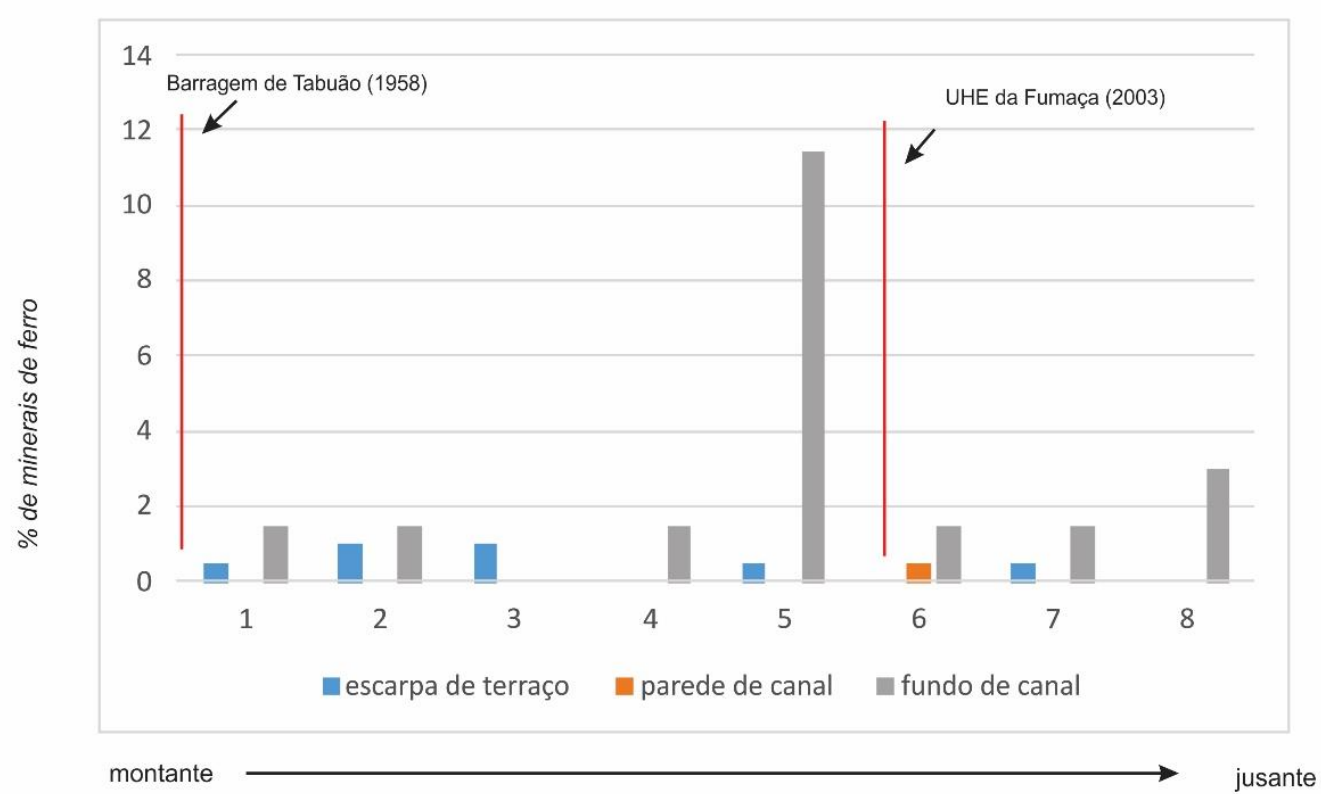

Figura 10 - Concentração de minerais de ferro em amostras obtidas nas escarpas dos terraços, nas paredes e no fundo dos canais ao longo do Rio Gualaxo do Sul. Ao longo do seu percurso foram construídas as barragens de Tabuão, em 1958 e a da Fumaça, em 2003.

Percentual de minerais de ferro nos sedimentos do alto Rio das Velhas

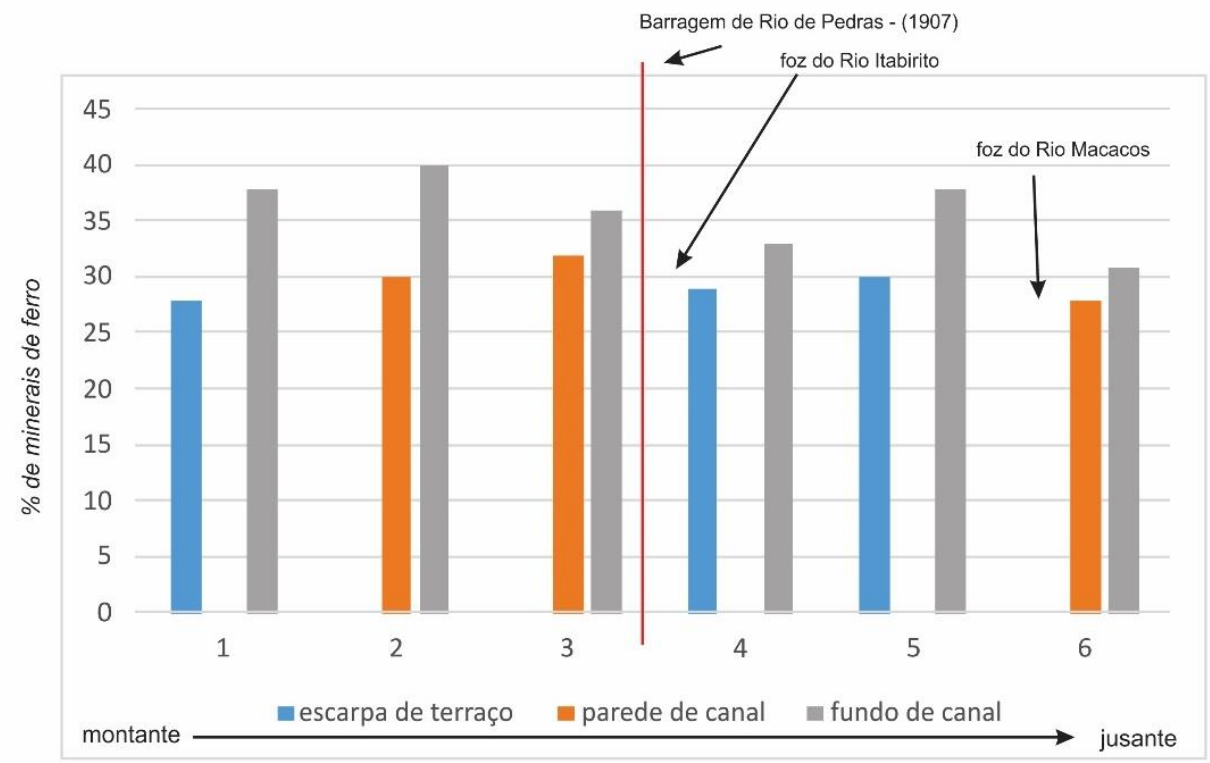

Figura 11 - Concentração de minerais de ferro em amostras obtidas nas escarpas dos terraços, nas paredes e no fundo dos canais ao longo do alto Rio das Velhas. Em 1907 foi construída a barragem de Rio de Pedras.

A figura 11 apresenta, por sua vez, a concentração de minerais de ferro na bacia do alto rio das Velhas, o posicionamento da foz do rio Itabirito e a barragem de rio de Pedras.

Analisando os dados levantados nos rios Piracicaba, Gualaxo do Norte, Gualaxo do Sul e alto Rio das Velhas pode-se perceber algumas tendências comuns a todos eles. Os valores máximos de concentração de minerais de ferro nas escarpas dos terraços sempre são menores do que os valores máximos encontrados nas amostras do fundo dos canais, como mostra a figura 6. Este mesmo comportamento está presente nos rios que não drenam áreas ricas em ferro, como mostra a Figura 7. Quanto às amostras obtidas nas paredes dos canais, os dados dos rios Gualaxo do Norte e do Sul não confirmam esta tendência. 
Os gráficos de concentração de minerais de ferro mostram uma diminuição da concentração de minerais de ferro em direção à foz dos rios, quer seja nas amostras de calha, das paredes dos canais e das escarpas dos terraços. Além disto, a concentração destes minerais é menor nas escarpas dos terraços e paredes dos canais em relação às existentes nas calhas para cada ponto amostrado. As divergências em relação a estas tendências gerais são associadas às incursões de afluentes provenientes de regiões ricas em ferro, ou às intervenções antrópicas ao longo dos eixos dos rios, como barragens.

No rio Piracicaba, por exemplo, as barragens parecem não fazer efeito na diminuição da concentração de minerais de ferro para jusante, à exceção da barragem de Antônio Dias, a mais antiga da região e que entrou em operação em 1951.

Talvez isto se deva ao fato de que à montante estejam situadas as fozes de dois afluentes que drenam importantes áreas mineradoras: o rio Santa Bárbara e o rio do Peixe. A alta concentração de minerais de ferro no ponto 7 do terraço à jusante da foz destes dois rios, pode se relacionar à erosão natural pré-colombiana nas suas cabeceiras.

No rio Gualaxo do Norte ocorre um aumento da concentração de minerais de ferro em amostras de calha à jusante da confluência do córrego Santarém, o que indicava a influência da mineração Samarco, a despeito da existência da barragem de Bicas que operou entre 1942 e novembro de 2015, quando foi destruída pela lama de rejeitos da ruptura da barragem de Fundão.

$\mathrm{O}$ rio Gualaxo do Sul não tem, na maior parte de suas cabeceiras, rochas ferruginosas, o que torna os sedimentos acumulados em seu leito os de menor concentração em minerais de ferro. Mesmo a maior concentração verificada nos sedimentos de calha à montante da Usina da Fumaça, em torno de $12 \%$, é menor do que as baixas concentrações nos demais rios estudados, à exceção dos tributários cujas nascentes não se encontram em rochas ferruginosas.

No alto Rio das Velhas, a concentração de minerais de ferro ao longo do canal é sempre superior à dos terraços e paredes do canal, tendo a tendência a diminuir para jusante, acompanhando a tendência geral dos rios.

Rios cujas cabeceiras nascem em áreas de mineração, como o Piracicaba, o Gualaxo do Norte e o Rio das Velhas, apresentam claramente uma tendência a ter mais minerais de ferro na fração areia do que os registrados em seus depósitos aluviais pré-industriais. Isto revela que, a despeito do atendimento à legislação em vigor e da fiscalização ambiental as obras de contenção de rejeitos e estéreis da mineração de ferro se mostram ineficazes.

\section{CONCLUSÕES}

Os estudos realizados nos sedimentos aluviais dos terraços e das calhas dos cursos de água das bacias hidrográficas cujas nascentes se encontram nas regiões serranas do Quadrilátero Ferrífero mostram que:

Os sedimentos de cursos de água com nascentes em formações ferríferas têm concentrações superiores de minerais de ferro ao longo de seus canais, em relação àquelas cujas nascentes drenam outros tipos rochosos;

De um modo geral, pelo fato de os minerais de ferro serem mais densos do que o quartzo, que é o principal mineral presente na fração areia em sedimentos fluviais, era de se esperar que houvesse uma diminuição da concentração dos minerais de ferro ao longo das calhas dos cursos de água estudados, das cabeceiras em direção as partes mais distais. No entanto esta tendência não é verificada devido ao impacto da mineração de ferro, a intensificação da explotação nas últimas décadas e ao uso de ferrovias para escoamento da produção bem como devido a construção de barragens nas calhas fluviais. Os sedimentos encontrados nos terraços, várzeas e nas calhas fluviais de cursos de água que drenam o Quadrilátero Ferrífero possuem concentrações de minerais de ferro que atingem até cerca de $80 \%$ dos minerais existentes nas amostras. Por ser uma região em cujas serras afloram rochas ferruginosas, é de esperar que os minerais de ferro estejam presentes em sedimentos de níveis deposicionais de diferentes idades. Para avaliar o impacto da mineração nos sedimentos depositados nas calhas fluviais optou-se por utilizar como base de comparação a concentração de minerais de 
níveis deposicionais pré-colombianos e, portanto, formados em tempos anteriores à industrialização.

As comparações realizadas mostram que mostram que as concentrações de minerais de ferro em sedimentos arenosos dos níveis deposicionais pré-colombianos são inferiores aos das concentrações em sedimentos semelhantes, porém depositados nas calhas fluviais. Tais dados indicam que a mineração de ferro é processo ativo na liberação de minerais de ferro na fração areia que está depositado nas calhas dos rios que drenam o
Quadrilátero Ferrífero, contribuindo com o assoreamento.

Os rejeitos liberados pela ruptura da barragem de uma mineradora em novembro de 2016 e que atingiram o rio Gualaxo do Norte e Doce é a expressão convulsiva e aguda desta contribuição, que vem somar-se aos processos crônicos que resultaram no entulhamento das calhas fluviais.

Ambos os processos de entulhamento, crônicos ou agudos, mostram a ineficiência das obras de contenção de rejeitos e estéreis das mineradoras da região.

\section{AGRADECIMENTOS}

O primeiro autor agradece à FAPEMIG o suporte oferecido em função do Programa Pesquisador Mineiro 2012-2014. Os autores agradecem as sugestões e discussões feitas pelos revisores que muito auxiliaram na clareza do texto final.

\section{REFERÊNCIAS}

ADDAD. J. E. Minerais pesados - uma ferramenta para prospecção, proveniência, paleogeografia e análise ambiental. Edição Independente. 80 p., 2001.

BACELLAR, L.A.P., COELHO NETTO, A.L., LACERDA, W.A. Controlling factors of gullying in the Maracujá Catchment, Southeastern Brazil. Earth Surface Processes and Landforms, v. 30, p. 1369-1385, 2005.

BARBOSA, G.V. \& RODRIGUES, D.M.S. O Quadrilátero Ferrífero e seus problemas geomorfológicos. Boletim Mineiro de Geografia, v.10/11, p. 3-35, 1965.

BARROS, L.F.P. Implicações geomorfológicas e paleoambientais de registros sedimentares fluviais do Quadrilátero Ferrífero - Minas Gerais. Belo Horizonte, 2015. 126 p. Tese (Doutorado em Geografia) - Instituto de Geociências. Universidade Federal de Minas Gerais.

BARROS, L.F.P., MAGALHÃES JR., A.P. Quaternary alluvial sedimentation in the Conceição river valley, southeastern Brazil. Brazilian Journal of Geology, v. 43, n. 3, p. 535-554 2013.

BOTSOU, F., KARAGEORGIS A.P., DASSENAKIS E., SCOULLOS M. Assessment of heavy metal contamination and mineral magnetic characterization of the Asopos River sediments (Central Greece). Marine Pollution Bulletin, v. 62, p. 547-563, 2011.

CHEREM, L.F.S., RAMOS, V.D.V., LOPES, F.W.A., MACEDO, D.R., MAGALHÃES JÚNIOR, A.P., SALGADO, A.A.R. Níveis e Sequiências Deposicionais Fluviais no Médio e Baixo Vale do Ribeirão do Caraça borda oriental do Quadrilátero Ferrífero/MG. In: ENCONTRO LATINO AMERICANO DE GEOMORFOLOGIA, 2, SIMPÓSIO NACIONAL DE GEOMORFOLOGIA, 7, 2008, Belo Horizonte. Anais.... Belo Horizonte: União da Geomorfologia Brasileira, 2008, CD-ROM.

COMPTON R.R. Geology in the field. New York. Wiley Ed., 398 p., 1985.

COSTA A.T., NALINI-JR H.A., CASTRO P.T.A., FRIESE K. Sediment contamination in floodplains and alluvial terraces as an historical record of gold exploitation in the Carmo River basin, Southeast Quadrilátero Ferrífero, Minas Gerais, Brazil. Acta Hydrochimica et Hydrobiologica, v. 34, p. 245-256, 2006.

COSTA, A.T. Geoquímica das Águas e Sedimentos da Bacia do Rio Gualaxo do Norte, Leste-Sudeste do Quadrilátero Ferrífero (MG): Estudo de uma Área Afetada por
Atividades de Extração Mineral. Ouro Preto, 2001. 147p. Dissertação (Mestrado em Ciências Naturais) - Escola de Minas, Universidade Federal de Ouro Preto.

COUTO D. C. Caracterização Geoquímica de Solos, Sedimentos e Águas em Sub-Bacias do Rio Das Velhas, no Quadrilátero Ferrífero, com Vistas a Reconhecer o seu Estado de Degradação. Ouro Preto, 2011. 71p. Trabalho de Conclusão de Curso (Engenharia Geológica) - Escola de Minas, Universidade Federal de Ouro Preto.

DNPM - DEPARTAMENTO NACIONAL DA PRODUÇÃO MINERAL. Sumário Mineral 2009, v. 29. Acesso em abril de 2016. 2015. Disponível em <https://sistemas.dnpm. gov.br/publicacao/mostra_imagem.asp?IDBancoArquivoArq uivo=4544>. Acesso em: 12 julho de 2011. 2009.

DNPM - DEPARTAMENTO NACIONAL DA PRODUÇÃO MINERAL. Ferro - Sumário Mineral 2014, v. 29. Disponível em <http://www.dnpm.gov.br/dnpm/sumarios/ferro-sumariomineral-2014>

FOLK, R. L. Petrology of sedimentary rocks. Austin, Hemphill Publishing Company, 185 p., 1980.

GUEDES, C.D.; GONÇALVES, C.D.; CASTRO, P.T.A.; MATSUMURA, M.S.; PAIVA, J.F.; LENA, J.C. Efeito da atividade mineira na dispersão de minério de ferro ao longo do alto e médio rio Piracicaba. Revista Brasileira de Recursos Hídricos, v. 10, p:89-95, 2005.

HALE, M.; PLANT, J.A. (Ed.) Drainage Geochemistry in Mineral Exploration. New York. Elsevier, 766p. 1994.

LANA, C.E., CASTRO, P.T.A. Variabilidade morfológica em níveis de base do rio Maracujá (Quadrilátero Ferrífero MG): influências litológicas, estruturais e de reativações cenozóicas. Revista Brasileira de Geomorfologia, v. 11, p:21-30, 2010.

LINDHOLM R. A Practical Approach to Sedimentology. London, George Allen \& Unwin, 276p. 1987.

MAGALHÃES JR, A.P., SAADI, A. Ritmos da dinâmica fluvial Neo-Cenozóica controlados por soerguimento regional e falhamento: o vale do rio das Velhas na Região de Belo Horizonte, Minas Gerais, Brasil. Geonomos, v. 2, n. 1, p:4254, 1994.

MAGALHÃES JR., A.P., BARROS, L.F.P., RAPOSO, A.A., CHEREM, L.F.S. Dinâmica fluvial quaternária do Rio Maracujá, Quadrilátero Ferrífero (MG). Revista Brasileira de Geomorfologia, v. 13, p:3-14, 2012. 
MENDONÇA F. P. C. 2012. Influência da mineração na geoquímica das águas superficiais e nos sedimentos no alto curso da bacia do ribeirão Mata Porcos, Quadrilátero Ferrífero - Minas Gerais. Ouro Preto, 2012. 131p. Dissertação (Mestrado em Ciências Naturais) - Escola de Minas, Universidade Federal de Ouro Preto.

MIALL A. D. The geology of fluvial deposits: sedimentary facies, basin analysis and petroleum geology. New York, Springer Verlag, 582 p. 1996

MOHIUDDIN, K. M.; ZAKIR, H. M.; OTOMO, K.; SHARMIN, S.; SHIKAZONO, N. Geochemical distribution of trace metal pollutants in water and sediments of downstream of an urban river. International Journal of Environmental Scicence Technologies., v. 7, n. 1, p: 17-28, 2010.

MORAES, M. E. M. Padrões de distribuição de minerais ricos em ferro nos sedimentos aluviais do alto curso do Rio das Velhas no Quadrilátero Ferrífero, MG: análise da dispersão natural e influência antrópica. Ouro Preto, 2015. 34 p. Trabalho de Conclusão de Curso (Engenharia Geológica), Universidade Federal de Ouro Preto.

PEREIRA, R. M., ÁVILA, C.R. \& LIMA, P.R.A.S. Minerais em Grãos: Técnicas de Coleta, Preparação e Identificação. São Paulo, Oficina dos Textos, 128p. 2005.

PETTIJOHN, F. J. Sedimentary Rocks. Third Ed. New York, Harper and Row Publishers, p. 628 p. 1975.

QUINTAES, M. Padrões de distribuição de minerais ricos em ferro nos sedimentos aluviais do Rio Gualaxo do Sul localizado na borda sudeste do quadrilátero ferrífero, MG: Análise da dispersão natural e da influência antrópica. Ouro Preto, 2014. 82 p. Trabalho de Conclusão de Curso (Engenharia Geológica) - Escola de Minas, Universidade Federal de Ouro Preto.

RAPOSO, A.A., OLIVEIRA, L.F., MAGALHÃES JÚNIOR, A.P., CHEREM, L.F.S. Níveis e sequências deposicionais do vale do ribeirão do Mango, Quadrilátero Ferrífero/MG. In: ENCONTRO LATINO AMERICANO DE GEOMORFOLOGIA, 2, SIMPÓSIO NACIONAL DE GEOMORFOLOGIA, 7, 2008, Belo Horizonte. Anais.... Belo Horizonte: União da Geomorfologia Brasileira, 2008, CD-ROM.

ROBERTTI, T.O. A dispersão natural e antrópica dos minerais de ferro na bacia do Rio Piracicaba, Minas Gerais, Brasil. Ouro Preto. 2016. Dissertação (Mestrado em Ciências Naturais) - Escola de Minas, Universidade Federal de Ouro Preto.
RODRIGUES, A.S.L. Caracterização da bacia do rio Gualaxo do Norte, MG, Brasil: avaliação geoquímica ambiental e proposição de valores de background. Ouro Preto. 2012. 184p. Tese (Doutorado em Ciências Naturais) Escola de Minas, Universidade Federal de Ouro Preto.

RODRIGUES, A.S.L., MALAFAIA, G., COSTA, A. T. \& NALINI, H.A.J. Evaluation of the Mineral Exploration Influence on Sediment Composition in the Gualaxo do Norte River Basin (MG-Brazil) based on geochemical and stratigraphic data. Environment Earth Sciences, v.68, p: 965-972. 2012.

SILVA, N. C. C. Padrões de distribuição de minerais ricos em ferro nos sedimentos aluviais da bacia do rio Itabirito localizado na porção sudoeste do Quadrilátero Ferrífero, MG: análise da dispersão natural e da influência antrópica. Ouro Preto, 2016. 40p. Trabalho de Conclusão de Curso (Engenharia Geológica) - Escola de Minas, Universidade Federal de Ouro Preto.

SOUZA, M.E.S. Padrões de distribuição de minerais ricos em ferro nos sedimentos aluvias dos afluentes do Rio Gualaxo do Norte localizado na borda sudeste do Quadrilátero Ferrífero, MG: Análise da dispersão natural e influência antrópica. Ouro Preto, 2013. 80 p. Trabalho de Conclusão de Curso (Engenharia Geológica) - Escola de Minas, Universidade Federal de Ouro Preto.

VALADÃO R.C., SILVEIRA J.S. Estratigrafia Quaternária e evolução do Relevo no Complexo do Bação, Dados Preliminares. Revista Escola de Minas, v. 45, p:85-87. 1992.

VARAJÃO A. C. A questão da correlação das superfícies de erosão do Quadrilátero Ferrífero, Minas Gerais. Revista Brasileira de Geociências, v. 21, n. 2, p: 138-145. 1991.

VICQ, R.; LEITE, M. G. P.; MENDONÇA, F.P.C. Geochemistry mapping: purpose of stream sediment mapping in two tropical basins, Brazil. In: INTERNATIONAL GEOLOGICAL CONGRESS, 34,2012, Brisbane. Proceedings... 2012. v. 1. p. 1-4.

VIGLIO, E.P; CUNHA, F.G. Atlas geoquímico da Bacia do Rio das Velhas. Belo Horizonte: Companhia de Pesquisa de Recursos Minerais. Programa Geologia do Brasil - Serviço Geológico do Brasil. Projeto Geoquímica Multiusos no Estado de Minas Gerais 1 CD-ROM. 2010.

Submetido em $1^{\circ}$ de setembro de 2016 Aceito em 28 de novembro de 2016 